\title{
Hardness and Roughness by AFM-HR Analysis of Nano-Hydroxyapatite
}

\author{
Dora E. Ledesma-Carrión \\ Dirección de Investigación, Instituto Nacional de Estadística y Geografí, Cd. de México, Cd. Mx., 03730 México
}

\begin{abstract}
Stoichiometric nano-hydroxyapatite is synthesized and compacted by UP (Uniaxial pressing) and CIP (Cold isostatic pressing). It is sintered (S) and subsequently is immersed in SBF (Synthetic body fluid). Hardness and roughness are analyzed in each part of process. The relationship between hardness and roughness is proportional after UP. While in the CIP and sintering the relationship is symmetric with a maximum. After immersion there is no clear functional relationship. Roughness changes at each stage of the process are $-13.3 \%(\mathrm{UP} \rightarrow \mathrm{CIP}), 22.10 \%(\mathrm{CIP} \rightarrow \mathrm{S})$ and $-61.5 \%(\mathrm{~S} \rightarrow \mathrm{SBF})$, respectively. Analogously, for area particle: $405.60 \%, 120.20 \%$ and $-99.8 \%$.
\end{abstract}

Key words: Hardness, roughness, atomic force microscopy, hydroxyapatite, compaction.

PACS: 01.30.-y, 01.30.Xx, 01.30.Tt.

\section{Introduction}

Hydroxyapatite is main bone substitute and its mechanical properties depend of grain size, porosity, density, hardness and toughness.

Atomic force microscopy and nano-indentation are surface analysis techniques, it is possible to measure a roughness and hardness of a sample surface at a high resolution, to distinguish a sample based on its mechanical properties, tests can be performed at variable displacements so that properties can be determined as a function changing substrate effect.

R. Roop Kumar and M. Wang [1] reported hardness, particle size and density of different samples of hydroxyapatite composites by nano-indentation and Fritsch particle size analyser, inter alia: HA- $\alpha$ TCP (2.56, 3.128, 1.5364; [GPa, $\left.\left.\mu \mathrm{m}, \mathrm{g} / \mathrm{cm}^{3}\right]\right)$, Spherical HA(6.76, 24,548, 2.9534), in-house-HA (6.19, 16,338, $2.9534)$ and $P 81 B(0.338,7,460,1.5657)$. The last one and spherical HA are commercial material and the other were by wet method [1]. Nano-rods-HA synthesized via the wet precipitation process of $\sim 50$

Corresponding author: Dora E. Ledesma-Carrión, PhD. Research fields: Biomaterials, optimization and mathematical models. $\times 15 \mathrm{~nm}^{2}$ and surface area of $120 \mathrm{~m}^{2} / \mathrm{g}$ by Wang and Shaw [2]. These have also been characterized by nano-indentation and BET method. Hardness follows the Hall-Petch relationship, $\sim 5.3 \mathrm{GPa}$ Knoop hardness, and particle size of $67 \mathrm{~nm}$ with heat treatment at $850{ }^{\circ} \mathrm{C}$ for densification. For the HAcc with 100-200 $\mathrm{nm}$ of diameter the Knoop hardness is 4.58-5.0 GPa. The Table 1 summarizes this informa- tion.

\section{Materials and Methods}

\subsection{Synthesis}

Hydroxyapatite was synthesized by coprecipitation method. A rod-like morphology with particle size of $20-50 \mathrm{~nm} \times 100-200 \mathrm{~nm}$, particle average size of $175.9 \mathrm{~nm}$ with 1 -modal, pore radii of $1.22 \mathrm{~nm}$ and stoichiometric and anisotropic hydroxyapatite was prepared by reacting calcium hydroxide and a phosphoric acid solution. Hydroxyapatite powder [3] was treated with heat at $680^{\circ} \mathrm{C}$ during $3 \mathrm{~h}$ in $\mathrm{Ar}$ atmosphere (HAcc).

\subsection{Compaction}

HAcc was submitted to cold uniaxial and isostatic compaction. The UP was a Daniels of Stroud Stryd glos 
Table 1 Density, diameter, roughness and hardness for different hydroxyapatites.

\begin{tabular}{lllll}
\hline Sample & $\begin{array}{l}\text { Density } \\
{\left[\mathrm{g} / \mathrm{cm}^{3}\right]}\end{array}$ & $\begin{array}{l}\text { Diameter } \\
{[\mathrm{nm}]}\end{array}$ & $\begin{array}{l}\text { Roughness } \\
{[\mathrm{nm}]}\end{array}$ & $\begin{array}{l}\text { Hardness } \\
\text { Hc }[\mathrm{GPa}]\end{array}$ \\
\hline HAcc UP & 1.7535 & 1,093 & 200.10 & 0.170 \\
HAcc CIP & 1.9301 & 2,028 & 247.25 & 0.518 \\
HAcc S & 2.0368 & 1,233 & 229.58 & 0.322 \\
HAcc SBF & 1.8367 & 74 & 90.39 & 3.208 \\
SHA* & 2.9534 & 24,548 & & 6.76 \\
In-house HA* & 2.8125 & 16.338 & 6.19 \\
aTCP* & 1.5364 & 3.128 & 2.56 \\
P81B* & 1.5657 & 7,460 & & 0.338 \\
P120* & 2.7989 & 3,290 & & 0.237 \\
P88* & 2.8125 & 4,530 & & 0.158 \\
\hline
\end{tabular}

*R. Roop Kumer, M. Wang.

No. 714987 RAM DIA 6". These tablets are named "green pieces". 5 g HAcc powder were compacted under $30 \mathrm{Kgf} / \mathrm{cm}^{2}$ during $90 \mathrm{~s}$. Dies diameter were $1.00-1.25 \mathrm{~cm}$ of steel 316L. CIP was made with a Yuken Model 334 press applied $400 \mathrm{MPa}$ during one cycle of four steps: Step 1: 0-100MPa; step 2: 101-200 $\mathrm{MPa}$; step 3: 201-300 MPa; step 4: 301-400 MPa. Time of step is $30 \mathrm{~s}$ [4].

\subsection{Sinter}

According to literature [5-7], there is nucleation from $600{ }^{\circ} \mathrm{C}$, but the best occurs at $1,350{ }^{\circ} \mathrm{C}$ for $7 \mathrm{~h}$. HAcc was sintered at $925^{\circ} \mathrm{C}$ in a process of one ramp: from 25 to $925^{\circ} \mathrm{C}$ at a rate of $10{ }^{\circ} \mathrm{C} / \mathrm{min}$, the carrier gas $\mathrm{Ar}$ is incorporated from $580^{\circ} \mathrm{C}$. And at $925^{\circ} \mathrm{C}$ it is maintained for $2 \mathrm{~h}$. After it allowed to cool at rate of $10{ }^{\circ} \mathrm{C} / \mathrm{min}$ up to get $25^{\circ} \mathrm{C}$ temperature. Ar turns off when it reaches $580{ }^{\circ} \mathrm{C}$. They will not be removed from the furnace until two days later to avoid thermal shock. Sintering was made in a 6000 Thermolyne $(0-$ $999^{\circ} \mathrm{C}$ ). Each tablet face was scanned into $50 \times 50$ $\mu \mathrm{m}^{2}$ areas for 5 zones and 1,250 scans/s. AFM-HR is a diMultiMode V - AFM Veeco, Nanoscope V controller, tapping mode, $50 \times 50 \mu \mathrm{m}^{2}$ areas and 1,250 scans/s. Silicon tip. Adjusted force of $50 \mu \mathrm{N}$.

\subsection{Bioactivity}

The grid is set to $70^{\circ} \mathrm{C}$ to keep the liquid at $36.5^{\circ} \mathrm{C}$ : $\mathrm{PH}=7.25$ with $50 \mathrm{mM}$ trihydroxy methyl-aminomethane and $45 \mathrm{mM}$ of hydrochloric acid. Ion concentrations and compounds for SBF used Kukobo et al. modified process [8].

Tablets enclosed inside assay tubes with $40 \mathrm{~mL}$ SBF were place into container. The tubes were immerged into thermic bath with ionized water at $37^{\circ} \mathrm{C}$. As tablets were drawn from the solution they were washed twice in deionized water and dried at room temperature for 2 days. When the tablets were taken out of SBF, liquid $\mathrm{pH}$ was measured and when dried them were weighed to record the change of $\mathrm{pH}$ and mass.

\section{Results and Discussion}

AFM analysis for pores and particles was applied on the tablets under UP, CIP, and later sintering. Finally, immersion into SBF during 1 day.

The analysis was applying the software indentation 4.16 and gwyddeon version 2.41. Track each tablet under each process was made. The results appear in Figs. 1 and 2 and Tables 1-3. Note: Hardness or roughness measures are not possible on all zones of samples, 10 zones for each sample.

The topographies of one tablet into each process step are showed in Fig. 1: (a) regular distribution in the UP, (b) rearrangement during the CIP, It is observed grooves and tetragonal symmetry of HAcc, (c) alignment of grooves after the sintering and (d) After immersing the tablets in SBF one day there is 

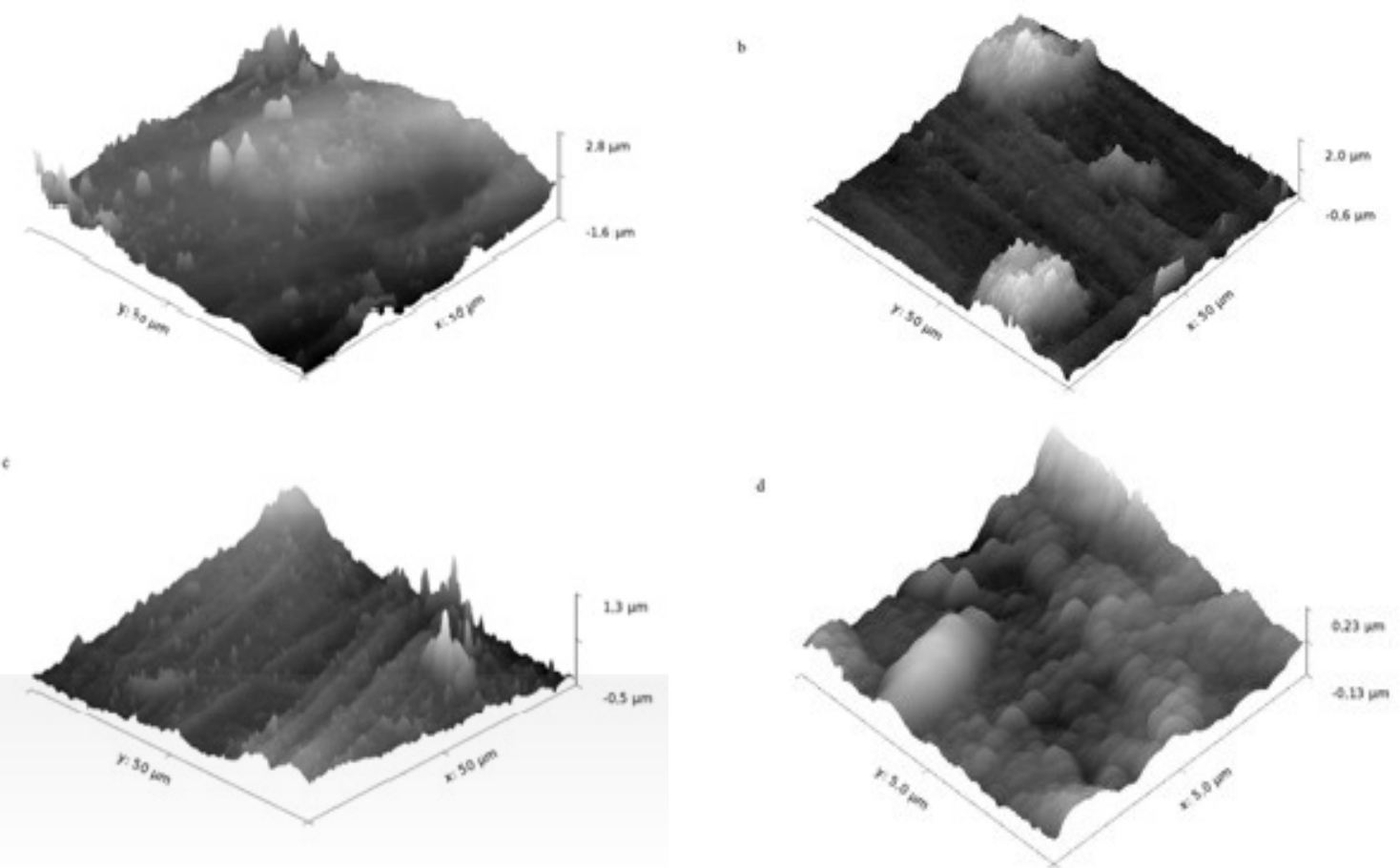

Fig. 1 AFM-HR, 3D images. Hydroxyapatite (HAcc) with (a) Uniaxial compaction (UP), (b) Isostatic compaction (CIP), (c) Sintering (S) and (d) Simulated body fluid (SBF) for 1 day.

Table 2 Summary of the analysis of particles for some zones samples of HAcc. roughness.

\begin{tabular}{|c|c|c|c|c|c|c|c|c|c|c|}
\hline \multirow{2}{*}{$\begin{array}{l}\begin{array}{l}\text { Sample } \\
\text { code }\end{array} \\
\text { Particle }\end{array}$} & \multirow{2}{*}{$\begin{array}{l}\begin{array}{l}\text { Average } \\
\text { roughness }\end{array} \\
{[\mathrm{nm}]}\end{array}$} & \multirow{2}{*}{$\begin{array}{l}\text { Standar } \\
\text { desviation } \\
\text { (s.d.) } \\
{[\mathrm{nm}]}\end{array}$} & \multicolumn{4}{|c|}{ Diameter $[\mathrm{nm}]$} & \multicolumn{4}{|c|}{ Area $\left[\mathrm{nm}^{2}\right]$} \\
\hline & & & Minimum & Maximun & Average & s.d. & Minimum & Maximun & Average & s.d. \\
\hline HA U 1 & 242.2 & 377.0 & 895.5 & $6,761.20$ & $2,006.30$ & $1,599.10$ & $629,881.60$ & $35,273,368.00$ & $5,064,248.00$ & $8,263,780.50$ \\
\hline HA U 2 & 151.3 & 225.2 & 895.5 & $7,275.40$ & $1,469.60$ & $1,188.80$ & $629,881.60$ & $41,572,184.00$ & $2,784,076.50$ & $6,510,063.00$ \\
\hline HA U 3 & 182.8 & 399.5 & 895.5 & $6,761.20$ & $1,500.40$ & $1,151.50$ & $629,881.60$ & $35,903,252.00$ & $2,778,889.30$ & $6,224,157.50$ \\
\hline HA I 1 & 303.2 & 541.9 & 895.5 & $15,091.90$ & $3,167.90$ & $3,670.50$ & $629,881.60$ & $178,256,480.00$ & $16,679,264.00$ & $39,503,888.00$ \\
\hline HA I 2 & 233.0 & 418.0 & 895.5 & $15,588.60$ & $5,527.10$ & $6,397.80$ & $629,881.60$ & $190,854,112.00$ & $51,965,228.00$ & $83,790,824.00$ \\
\hline HA I 3 & 67.1 & 103.0 & 895.5 & $2,831.90$ & $1,261.20$ & 590.40 & $629,881.60$ & $6,298,816.00$ & $1,502,025.30$ & $1,616,937.30$ \\
\hline HA I 4 & 63.3 & 94.5 & 895.5 & $3,102.20$ & $1,266.80$ & 545.10 & $629,881.60$ & $7,558,579.00$ & $1,490,424.00$ & $1,476,203.10$ \\
\hline HA S 1 & 285.6 & 462.0 & 895.5 & $15,144.90$ & $2,703.10$ & $3,368.80$ & $629,881.60$ & $179,516,256.00$ & $14,361,300.00$ & $40,729,932.00$ \\
\hline HA S 2 & 83.1 & 124.8 & 895.5 & $6,139.50$ & $1,974.80$ & $1,776.00$ & $629,881.60$ & $29,604,434.00$ & $5,374,989.50$ & $9,077,624.00$ \\
\hline HA S 3 & 335.1 & 444.7 & 895.5 & $9,306.70$ & $1,598.60$ & $1,468.80$ & $629,881.60$ & $68,027,208.00$ & $3,662,102.30$ & $10,735,525.00$ \\
\hline \multicolumn{11}{|c|}{ U-uniaxial compression, I-isostatic compression and S-sinterized. } \\
\hline $\begin{array}{l}\text { Sample } \\
\text { code }\end{array}$ & $\begin{array}{l}\text { Average } \\
\text { roughness }\end{array}$ & $\begin{array}{l}\text { Standar } \\
\text { desviation } \\
\text { (s.d.) }\end{array}$ & \multicolumn{4}{|c|}{ Diameter [nm] } & \multicolumn{4}{|c|}{ Area $\left[\mathrm{nm}^{2}\right]$} \\
\hline Particle & {$[\mathrm{nm}]$} & {$[\mathrm{nm}]$} & Minimum & Maximun & Average & s.d. & Minimum & Maximun & Average & s.d. \\
\hline HA-1 SBF & 53.925 & 80.348 & 44.424 & 421.447 & 81.179 & 68.725 & $1,550.003$ & $139,500.281$ & $8,862.595$ & $18,943.316$ \\
\hline HA-2 SBF & 112.040 & 210.635 & 44.424 & 453.042 & 83.985 & 81.313 & $1,550.003$ & $145,700.297$ & $10,141.449$ & $25,163.076$ \\
\hline HA-3 SBF & 227.380 & 432.022 & 44.424 & 446.459 & 68.103 & 48.033 & $1,550.003$ & $150,350.297$ & $5,397.133$ & $13,764.532$ \\
\hline HA-5 SBF & 37.073 & 66.361 & 44.424 & 423.782 & 61.709 & 49.070 & $1,550.003$ & $141,050.281$ & $4,856.676$ & $16,418.199$ \\
\hline
\end{tabular}


Table 3 Comparison per process: uniaxial compaction, isostatic compaction, sintering and simulated body fluid.

\begin{tabular}{|l|l|l|l|l|l|}
\hline $\begin{array}{l}\text { Sample } \\
\text { particle }\end{array}$ & $\begin{array}{l}\text { Average roughness } \\
{[\mathrm{nm}]}\end{array}$ & $\begin{array}{l}\text { Difference by process } \\
\text { Process } U \rightarrow I \rightarrow S\end{array}$ & $\begin{array}{l}\text { Sample } \\
\text { particle }\end{array}$ & $\begin{array}{l}\text { Average roughness } \\
{[\mathrm{nm}]}\end{array}$ & $\begin{array}{l}\text { Difference by process } \\
\text { Process } U \rightarrow I \rightarrow S \rightarrow S B F\end{array}$ \\
\hline HA U & 192.139 & & HA SBF & 90.39 & $-54.8 \%$ \\
\hline HA I & 166.674 & $-13.3 \%$ & & & Process $S \rightarrow S B F$ \\
\hline HA S & 234.615 & $22.1 \%$ & & $-61.5 \%$ \\
\hline Sample & Average diameter & Difference by process & Sample & Average diameter & Difference by process \\
\hline $\begin{array}{l}\text { particle } \\
\text { HA U }\end{array}$ & {$[\mathrm{nm}] 1658.790$} & process $U \rightarrow I \rightarrow S$ & $\begin{array}{l}\text { particle } \\
\text { HA SBF }\end{array}$ & [nm] 73.7 & $\begin{array}{l}\text { Process } U \rightarrow I \rightarrow S \rightarrow S B F \\
-95.6 \%\end{array}$ \\
\hline HA I & 2805.744 & $69.1 \%$ & & & Process $S \rightarrow S B F$ \\
\hline HA S & 2092.178 & $26.1 \%$ & & & $-96.5 \%$ \\
\hline Sample & Average area & Difference by process & Sample & Average area & Difference by process \\
\hline $\begin{array}{l}\text { particle } \\
\text { HA U }\end{array}$ & {$\left[\mathrm{nm}^{2}\right] 3,542,404.58$} & process $U \rightarrow I \rightarrow S$ & $\begin{array}{l}\text { particle } \\
\text { HA SBF }\end{array}$ & [nm $\left.{ }^{2}\right] 7,314.50$ & $\begin{array}{l}\text { Process } U \rightarrow I \rightarrow S \rightarrow S B F \\
-99.8 \%\end{array}$ \\
\hline HA I & $17,909,235$ & $405.6 \%$ & & & Process $S \rightarrow S B F$ \\
\hline HA S & $7,799,464$ & $120.2 \%$ & & & $-99.9 \%$ \\
\hline
\end{tabular}

HA-hydroxyapatite HAcc; U-uniaxial compaction; I-cold isostatic compaction; S-sintering; SBF-Simuated body fluid.
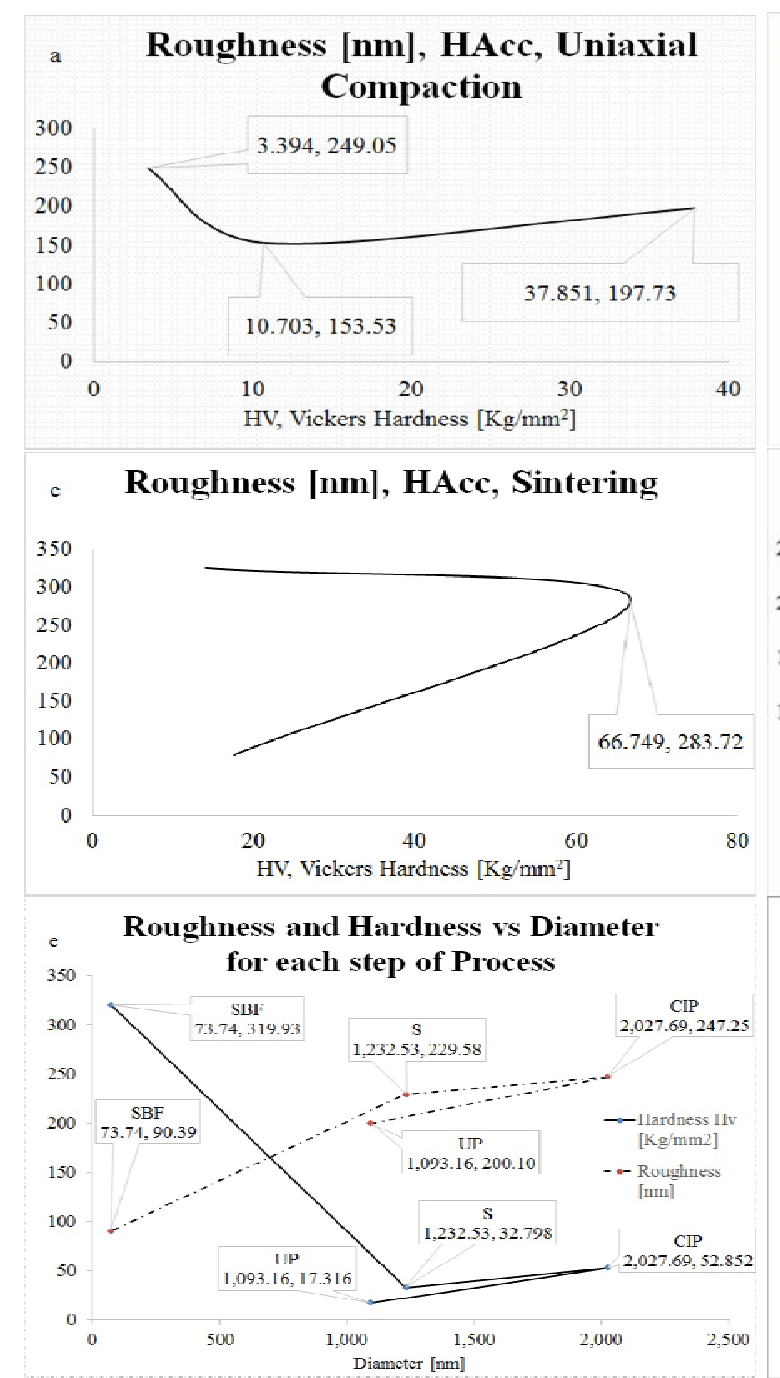

b Roughness [nm], HAcc, Isostatic compaction

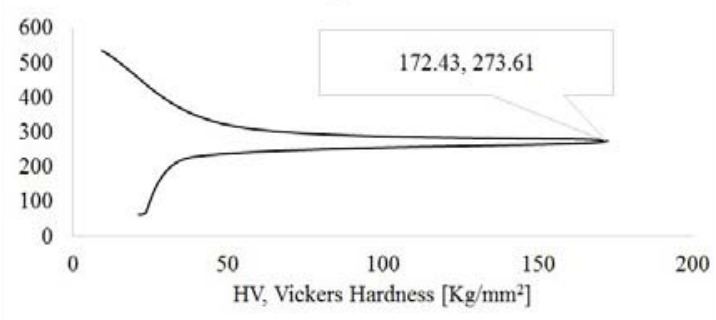

Roughness [nm], HAcc, Simulated Body Fluid

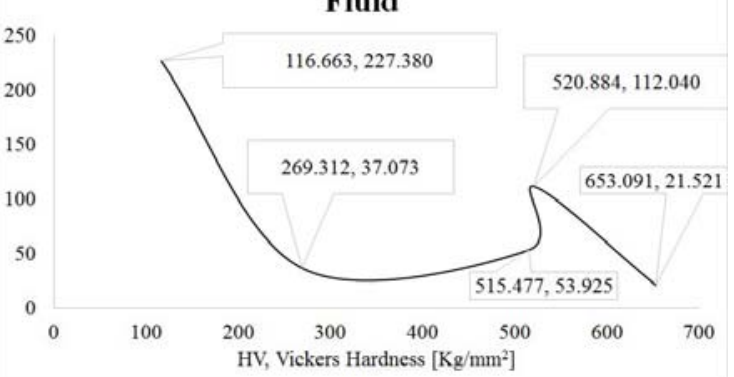

f Roughness and hardness vs Density

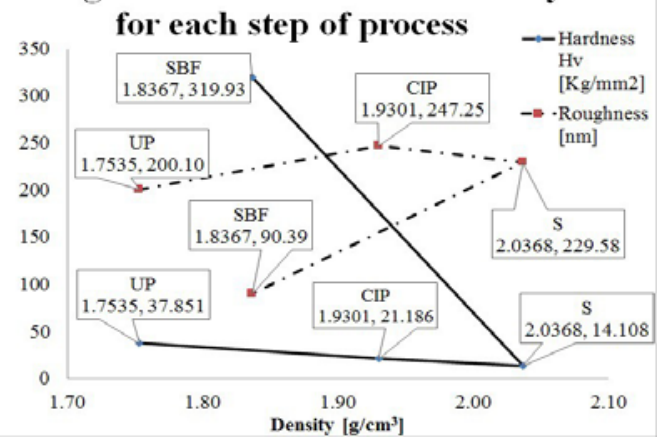

Fig. 2 Maximal hardness versus roughness in each track of process. (a) uniaxial compaction (UP), (b) isostatic compaction (CIP), (c) sintering (S) and (d) simulated body fluid (SBF) 1 day, (e) roughness, hardness vs diameter in each step of process and, (f) roughness, hardness vs density in each step of process. 
evidence of the diffusion process, face appears smoothed with rounded structures.

From Table 1, HAcc SBF has similar mechanical properties that $\alpha$-TCP (Hc) and HA-Wang-Shaw (Knoop hardness), and HAcc S with P81B (density). From Tables 2 and 3, the increase is observed in the size of particle after CIP $69.1 \%$ with regard to the "green" tablet (after UP). During sinter it is reduced up to $25.43 \%$. Drastic particle size reduction occurs in the SBF. The total effect is a decreasing of 95.6\%. The same behavior is shows for particle area. During the UP the particles agglutinate increasing the spaces inter-grains. Later, during the CIP the particles re-get accommodated increasing the size of grain. Finally, after sinter them, the particles return to agglutinate again. Tablets gain in nano-hardness (and elasticity [4]).

The liquid $\mathrm{pH}$ where tablets were immerged during one day is 8 (initial $\mathrm{pH}=7.25$ ) with a $41.2 \%$ loss weight.

\section{Conclusions}

There is a direct relationship between hardness and roughness after UP from $10,703 \mathrm{Kg} / \mathrm{mm}^{2}$ with a slope of 1.6. After CIP both maximum hardness and roughness are reached in the central part of the tablet. Subsequently, sintering, the maximum hardness is reduced $38.7 \%$ and the roughness increased by $3.69 \%$. Finally, there is no direct relationship between hardness and roughness after immersion in synthetic body fluid. This is evidence of the presence of chemical reactions.

\section{References}

[1] Kumar, R. R. and Wang, M. 2002. "Modulus and Hardness Evaluations of Sintered Bioceramic Powders and Functionally Graded Bioactive Composite by Nano-Indentation." Materials Science and Engineering A 338: 230-6.

[2] Wang, J. and Shaw, L. 2009. "Nanocrystalline Hydroxyapatite with Simultaneous Enhancements in Hardness and Toughness." Biomaterials 30: 6565-72.

[3] Ledesma-Carrión, D. E. 2015. "Modification on the Synthesis Process of Hydroxyapatite, Asian Journal of Science and Technology." 6 (4): 1311-5.

[4] Ledesma-Carrión, D. E. 2015. "Nano-Hardness and Elasticity for Hydroxyapatite Before and After of Immersing it into Simulated Body Fluid.” International Journal of Emerging Trends in Science and Technology 2 (6): 2704-9.

[5] Ohgaki, M., Nakamura, S., Okura, T. and Yamashita, K. 2000. "Enhanced Mineralization on Electrically Polarized Hydroxyapatite Ceramics in Culture Medium.” J. Ceram. Soc. Japan 11 (108):1037-40.

[6] Chun-Hway, H. 1991. "Some Considerations of Determination of Residual Stresses and Young's Moduli in Ceramic Coatings." J. Am. Ceram. Soc. 74:1646-9.

[7] Afshar, A., Ghorbani, M., Ehsani, N., Saeri, M. R. and Sorrel, C. C. 2003. "Some Important Factors in Wet Precipitation Process of Hydroxyapatite." Materials \& Design, Num. 24: 197-202.

[8] Oyane, A., Kim, H. -M., Furuya, T., Kokubo, T., Miyazaki, T. and Nakamura, T. 2003. "Preparation and Assessment of Revised Simulated Body Fluids." Journal of Biomedical Materials Research 65 A: 188-95. 